\title{
Study of quantitative genetics of gum arabic production complicated by variability in ploidy level of Acacia senegal (L.) Willd
}

\author{
Adja Madjiguene Diallo ${ }^{1,2}$ • Lene Rostgaard Nielsen ${ }^{1}$ - Jon Kehlet Hansen ${ }^{1}$. \\ Anders Ræbild ${ }^{1}$ Erik Dahl Kjær ${ }^{1}$
}

Received: 9 January 2015 /Revised: 7 May 2015 / Accepted: 9 June 2015 / Published online: 14 July 2015

(C) The Author(s) 2015. This article is published with open access at Springerlink.com

\begin{abstract}
Gum arabic is an important international commodity produced by trees of Acacia senegal across Sahelian Africa, but documented results of breeding activities are limited. The objective of this study was to provide reliable estimates of quantitative genetic parameters in order to shed light on the breeding potential for improvement of gum yield and quality. For this purpose, we measured growth on 617 offspring from 60 open-pollinated trees after 18 years, and gum yield and quality based on two seasons, 18 and 19 years after establishment. Genotyping with eight microsatellite markers revealed that progenies consisted of both diploid and polyploid trees, and growth, gum yield, and gum quality varied substantially among ploidy level, populations, and progenies. Analysis of molecular variance and estimates of outcrossing rate supported that trees within open-pollinated families of diploids were half sibs, while the open-pollinated families of polyploids showed low variation within families. The difference in sibling relationship observed between ploidy levels complicated estimation of genetic parameters. However, based on the diploid trees, we conclude that heritability in gum arabic production is low to high with presence of high levels of additive genetic variation, although the genetic
\end{abstract}

Communicated by D. Grattapaglia

This article is part of the Topical Collection on Complex Traits

Adja Madjiguene Diallo

madjidiallo@yahoo.fr; adi@ign.ku.dk

1 Department of Geosciences and Natural Resource Management, University of Copenhagen, Rolighedsvej 23, 1958 Frederiksberg $\mathrm{C}$, Denmark

2 Centre National de Recherches Forestières/Institut Sénégalais de Recherches Agricoles (CNRF/ISRA), Route des Peres Maristes, BP 2312 Dakar, Senegal parameters could only be estimated with fairly high standard error. The findings suggest that improvement through breeding can increase the productivity of $A$. senegal substantially. However, the results also stress the importance of testing ploidy levels of selected material and use of genetic markers to qualify the assumptions in the quantitative genetic analysis.

Keywords Mating system $\cdot$ Senegalia senegal $\cdot$ Breeding · Genetic parameters · Gum arabic · Growth · Microsatellite markers

\section{Introduction}

Acacia senegal (L.) Willd. is one of the most important tree species in Africa, and the species distribution area occupies more than $50 \%$ of the sub-Saharian regions in Africa (Odee et al. 2012). The species is famous for its gum arabic, a dried exudate rich in soluble fibers, which emerges from slits made in the bark of the stems and branches and tapped by the local populations. It is a multipurpose species that besides gum arabic provides valuable livestock fodder and fuel wood (Raddad and Luukkanen 2006a). The species can restore soil fertility because of its ability to fix $\mathrm{N}_{2}$, which is beneficial for crop production in the gum arabic agroforestry systems in drylands of sub-Saharan Africa (Raddad and Luukkanen 2006b). The gum is an international commodity used in food, pharmaceutical, and cosmetic industries and for a wide range of other purposes (Fagg and Allison 2004). Between 2003 and 2007, the European Union, which is the largest overseas market for gum arabic, imported about 200,000 tons amounting to close to US\$432 million (MNS 2008). Sixty percent of the world production came from Sudan, while $24 \%$ came from Chad, $6 \%$ from Nigeria, and $8 \%$ from other minor producing countries (Couteaudier 2007; Touré 2009). The collection and 
sale of gum arabic can be especially important for rural populations as it is produced in the dry season when other income opportunities are limited and allows families to earn up to US\$150/month during this period (Fagg and Allison 2004).

In Senegal, the species is one of the most economically and ecologically important native tree species covering the northern and eastern regions of the country. Historically, Senegal used to be the second largest producer of gum arabic in Africa after Sudan until the 1960s when severe drought struck the gum belt in West Africa and an $80 \%$ loss of gum forests was reported (Wate 1979; Coulibaly 1988). At present, Senegal supplies only $1 \%$ of the world market. In order to increase production, it is important to identify high-yielding trees adapted to the dryland ecosystems for future breeding. To implement effective breeding strategies, knowledge is needed of the genetic architecture behind the inheritance of the traits of interest, but until present, there is only little knowledge on the genetics of the species.

A. senegal was one of the earliest domesticated species in tropical drylands, but still only few studies have provided reliable information on genetic variation in gum yield (Ouédraogo 2001; Raddad and Luukkanen 2006a, b; Larwanou et al. 2010; Soloviev et al. 2010). Previous prebreeding initiatives have involved establishment of provenance trials across the geographic range of the species in Senegal, Burkina Faso, Niger, and Sudan in order to test the variation among provenances. In Africa, it is rare to support tree breeding with results derived from molecular data. One of the few exceptions is the recent study of leaf production of Adansonia digitata (Korbo et al. 2013), where genetic parameters were adjusted to account for likely high selfing rates based on findings of Larsen (2010). On a global scale, molecular studies have only been integrated in breeding of a few tropical and sub-tropical tree species such as Acacia mangium and Acacia auriculiformis (Butcher et al. 1998), Elaeis guineensis (Wong and Bernando 2008), and Eucalyptus species (Grattapaglia et al. 2009; Grattapaglia and Kirst 2008; Henery et al. 2007). The vast majority of tree breeding activities are based on standard assumptions regarding mating system and Mendelian segregation even though there is increasing evidence from a number of species showing that this may not always be valid. For $A$. senegal, it was recently disclosed that more than one level of ploidy exists within the natural distribution of the species (Assoumane et al. 2013).

An improvement program for $A$. senegal has been developed in Senegal by Centre National de Recherches Forestieres since 1994 based on selection of superior trees (plus trees) and establishment of two progeny tests in Dahra and Bambey to test the offspring from the selected trees. These trials represent the first breeding cycle, and the aim of the present study was to estimate the heritability for growth and gum production based on observations from the field trials, supported by genetic data based on microsatellite markers of the tested trees.
Previous studies of gum yield and quality in provenance trials and natural stands have reported large variation within and among populations in gum yield (Ballal et al. 2005; Raddad and Luukkanen 2006a, b; Sprent et al. 2010) and quality (Chikamai and Odera 2002; Lelon et al. 2010). Both gum yield and quality are complex traits where the biological variability remains poorly understood, but is likely to involve influences of both genetics and environment. To our knowledge, there are no published estimates of additive genetic heritability for gum production where molecular markers were applied to support the quantitative genetic analysis. The presence of different levels of ploidy in A. senegal makes this study particularly interesting as it has been shown that polyploids are more drought tolerant compared with diploids (Diallo et al. 2015, unpublished) and because some studies have indicated that gum production is correlated to the reduction of water storage in the soil (Vassal and Dione 1993; Anderson 1995; Wekesa et al. 2009). On this background, the specific objectives of the present study was first to determine sibling relationship of the progeny based on microsatellite markers. Secondly, to estimate additive genetic variation and narrow-sense heritability for gum yield/quality and growth traits in order to increase understanding of the inheritance of these traits essential for estimation of expected responses from selection (Falconer and Mackay 1996). Finally, we will compare and discuss likely importance of the observed genetic variation within and between diploid and polyploid families, and the potential for restoring high gum productivity of the trees in Senegal by artificial selection and breeding.

\section{Materials and methods}

Gum trees derived from open-pollinated seed collected from 60 trees from four natural populations (Diamenar, Ngane, Daiba, and Kidira) were used in this study. The trees were established in a progeny test in Dahra $\left(15^{\circ} 20^{\prime} \mathrm{N}\right.$ and $15^{\circ}$ $\left.28^{\prime} \mathrm{W}\right)$ in 1994 with randomized complete single tree blocks with 15 families per provenance replicated 30 times (30 blocks) in a balanced design with $5 \times 5 \mathrm{~m}$ spacing.

\section{Phenotypic characters}

Eighteen years after planting (in 2012), the following quantitative traits were assessed in all 617 surviving trees in the trial: tree height, diameter $30 \mathrm{~cm}$ above ground, and crown diameter (mean of two perpendicular crown diameter measures).

Gum yield was assessed during two consecutive years (2012 and 2013) according to the following sampling design:

The gum yield was assessed in 416 random trees (289 diploids and 127 polyploids) targeting 10 trees per family per provenance. Both levels of ploidy were represented in 
each provenance except for the Diamenar provenance where all tapped trees were diploids (118 individuals). In the Kidira and Daiba provenances, 77 diploids versus 14 polyploids and 74 diploids versus 11 polyploids were tapped, respectively, while the Ngane provenance gum sampling was from 102 polyploid and 20 diploid trees. Incisions were made in the bark of branches to promote exudation of gum in the end of November of each year where the progressive loss of foliage was used as an indicator for the correct timing of tapping. The incisions were made using a local tool, the Daba. The number of branches for tapping and the length of the incision varied among trees reflecting the traditional tapping practice, where branches having diameter above $3 \mathrm{~cm}$ can be tapped by removing $4 \mathrm{~cm}$ wide and $30 \mathrm{~cm}$ to $1 \mathrm{~m}$ long strips of bark to expose the sapwood. The first gum was collected from the tapped trees in mid- December. The incisions were refreshed in beginning of January and thereafter, gum was monthly harvested until the exudation stopped (end of April). Gum yield from each individual was kept separately and weighted individually. In total, four harvests were made each season (2012/2013 and 2013/2014). The sampling was not balanced, because some families had less than ten living trees.

\section{Color, nitrogen, and carbon contents of gum arabic}

Five random families out of the 15 families of each provenance were selected for study of color, nitrogen and carbon contents of the gum arabic. In each selected family, gum was collected from four random trees in the progeny trial. Gum availability varied among the selected trees creating some unbalance and only 72 gum samples were analyzed because eight trees in the sampled families did not produce sufficient gum for testing. Gum color is a quality criterion in some parts of the confectionary industry, which tend to favor brighter colors as the color can more easily be changed. Gum surface color was determined using the Munsell Soil Color Chart (Gretag Macbetch 1998, New York). The system has three components: a hue representing a specific color, a value showing the lightness or darkness of the color in question and the chroma, which represents the strength or the concentration of the hue in the sample. Therefore, the color of a gum sample was determined on the basis of these three components arranged in a book of color chips. The gum samples were held next to the chips to find a visual match and assign the corresponding Munsell notations. For each gum sample, the hue value, lightness/darkness value and chroma value were recorded. Four different combinations of values were observed in this study and each sample could therefore be classified into one of the four different color classes: class $1,7.5$ yellow red (YR) $5 / 8=$ strong brown; class $2,7.5$ YR $6 / 8=$ reddish yellow; class 3, 10 YR 6/8=brownish; and class 4, 10 YR 8/4=very pale brown.
The nitrogen and carbon contents were analyzed using a CN Analyzer (CN Soil Analyzer, Thermo Scientific Flash 2000). Following complete combustion of the sample at $950{ }^{\circ} \mathrm{C}$, each compound was converted into elemental gases and detected by a chromatography column connected to a highly sensitive thermal conductivity detector. Following the manufacturer's protocole, the gum was ground before analysis in a disruptor (MM301, Retsch, Haan, Germany) and $9 \mathrm{mg}$ was weighed in tin capsules (Sercon SC 0009, UK). A reference material (Picea leaf) with known nitrogen and carbon content was run initially in order to obtain a standard curve.

\section{DNA analysis}

Total genomic DNA was isolated from all 617 trees present in the progeny trial. Nine milligrams of dried cambium were frozen in liquid nitrogen and ground on a bead mill (MM301, Retsch, Haan, Germany). Extractions were conducted with DNeasy 96 Plant kit, Qiagen, Hilden, Germany, following the manufacturer's protocol for dry material. The DNA solutions were kept undiluted, and the genotyping was performed using eight polymorphic microsatellites markers (Cirb10, Cire10, Cirf02, Cirf03, Circ07, Cire06, Cire08, and Cirh09) developed by Assoumane et al. (2009). The PCR amplification was done using two primer mixes prepared as described below: in mix $1,5 \mu$ of both forward and reverse primer stock solutions (each of $100 \mu \mathrm{M}$ ) was used for Cirb10 and $\mathrm{Cirf03}$ and $10 \mu \mathrm{l}$ of Cire10 and Cirf02 and adjusted with $440 \mu \mathrm{H}_{2} \mathrm{O}$ to a final volume of $500 \mu \mathrm{l}$. Mix 2 consisted of a mixture of $10 \mu \mathrm{l}$ of both reverse and forward stock primers $(100 \mu \mathrm{M})$ of Cirh09, Cire08, Circ07, and Cire06 and $420 \mu \mathrm{l}$ of RNAse-free water. PCR was carried out using the Qiagen Multiplex PCR kit according to the manufacturer's instructions except that the reaction volume was scaled down to $10 \mu \mathrm{l}$. PCR amplifications were conducted in an Applied Biosystems (Carlsbad, CA, USA) PCR system 2700 and Bio-Rad C1000 Thermal cycler under the following conditions: initial denaturation of $15 \mathrm{~min}$ at $95{ }^{\circ} \mathrm{C}, 30$ cycles of denaturation at $94{ }^{\circ} \mathrm{C}$ for $30 \mathrm{~s}$, annealing at $57{ }^{\circ} \mathrm{C}$ for $90 \mathrm{~s}$, and extension at $72^{\circ} \mathrm{C}$ for $60 \mathrm{~s}$ and a final extension step at $60^{\circ} \mathrm{C}$ for $30 \mathrm{~min}$.

Each PCR product was diluted with $160 \mu \mathrm{l} \mathrm{H}_{2} \mathrm{O}$. Microsatellite fragments were visualized with an Applied Biosystems ABI3130xL sequencer using GeneScan 500LIZ as internal standard.

\section{Ploidy level determination}

The microsatellite markers allowed us to classify all 617 living individuals in the progeny trial as diploid (max two bands at any of the genotyped loci) or polyploid (more than two bands at any of the genotyped loci), but differentiation between triploid and tetraploid individuals was not possible using this 
approach. The remote location of the trial (Senegal) made the determination of the exact ploidy level of all trees difficult using flow cytometry which is based on fresh leaves. Therefore, twigs from a subset of the trees (59) already genotyped was collected and put in water until flushing. Fresh leaves were then analyzed using a Partec PA II flow cytometer with DAPI as staining solution (Otto 1990).

Histogram of diploid individuals was localized on channel 50 corresponding to one large (2C) and one small (4C) peak; whereas, tetraploid individuals had their peak on channel 100 and showed one major $4 \mathrm{C}$ peak, a small $8 \mathrm{C}$ peak, and no $2 \mathrm{C}$ peak. Triploid trees had their histogram in between.

\section{Molecular analysis}

As recently discovered in a study comparing the growth of polyploid and diploid A. senegal, our progeny trial consists of pure diploid families, pure polyploid families, and mixed families that contain both diploid and polyploid individuals (Appendix). At provenance level, the highest fraction of diploid individuals was found in Diamenar provenance (98\%) while the Daiba, Kidira, and Ngane provenances consisted of 90,86 , and $17 \%$ of diploid trees, respectively.

To compare the genetic relationship of all individuals across provenances and ploidy level, microsatellite markers were treated as dominant markers and data were coded as present (1) or absent (0) for each allele at all loci in each individual. In this scheme, each allele (or band) at a codominant locus is treated as an independent dominant marker with two states 0 or 1 . The converted data were then analyzed in GenAlex version 6.5 (Peakall and Smouse 2012).

Principal coordinate analysis ( $\mathrm{PCoA})$ as implemented in GenAlex version 6.5 (Peakall and Smouse 2012) was used to visualize the genetic relationship among all individuals. Within each provenance, individuals were divided into two groups according to their ploidy. Therefore, eight groups of individuals (i.e., Diploid Diamenar, Diploid Daiba, Diploid Kidira, Diploid Ngane, Polyploid Diamenar, Polyploid Daiba, Polyploid Kidira, and Polyploid Ngane) were analyzed. As input file, a pairwise individual-by-individual genetic distance matrix was constructed using the binary data set described above. The distance between each individual pair was calculated as described in Huff et al. (1993).

In order to assess the distribution of the variation within and among families for each provenance, an analysis of molecular variance (AMOVA) was conducted. For the predominantly diploid provenances, pairwise genetic distances between individuals were calculated from both phenotype (when scored as dominant markers) and genotype (when scored as co-dominant markers) in separate analyses, polyploid individuals being excluded from the analysis. In the predominatly polyploid provenance Ngane, the AMOVA was only performed on polyploid individuals using only binary data.
Differentiation among family within each population was calculated based on both co-dominant and binary data according to the formula:

$\varphi_{A F}=\mathbf{V}_{\mathbf{A F}} /\left(\mathbf{V}_{\mathbf{W F}}+\mathbf{V}_{\mathbf{A F}}\right)$

where $\mathbf{V}_{\mathbf{W F}}$ and $\mathbf{V}_{\mathbf{A F}}$ are the estimates of variance in genetic distances between trees within and among families within each provenance, respectively.

The mating system of the predominantly diploid provenances (Diamenar, Kidira, and Daiba) was estimated based on genotypes of diploid individuals (ignoring the relatively few polyploids).

The multilocus mixed-mating model of Ritland (2002) as implemented in MLTR (version 3.2, 2008) was applied to estimate the mating system. The following mating system parameters were calculated: (i) multilocus outcrossing rates $\left(t_{\mathrm{m}}\right)$; (ii) single-locus outcrossing rates $\left(t_{\mathrm{s}}\right)$; (iii) the difference between multilocus and single-locus estimates of outcrossing $\left(t_{\mathrm{m}}-t_{\mathrm{s}}\right)$, which characterizes the level of biparental inbreeding (Ritland 2002), and (iv) the correlation of paternity within families $\left(r_{\mathrm{p}}\right)$. We used the Newton-Raphson algorithm for estimations as implemented in the MLTR program. Confidence intervals were obtained using 1000 bootstraps. We assume the three tested provenances have different pollen clouds as they originate from different sites in Senegal, and calculations were therefore performed independently for the three provenances. Prior to analysis, we removed 18 individuals that did not fit with the expected mother genotypes. The effective number of male parents $N_{\text {ep }}$ was estimated from $r_{p}$. A low level of correlation between male gametes within the open-pollinated families - i.e., large estimates of $N_{\mathrm{ep}}$ - was considered as a strong indication of half-sib relationships among trees within families.

\section{Statistical analysis of growth and yield data}

Statistical analyses were performed using the procedure general linear model (GLM) with the Satterthwaite option for the tests as implemented in the statistical software SAS 9.3 (SAS Institute 2014). The analyses of variance were done in two steps, where the first step involved a test of the effects of ploidy level. Growth traits were already shown to be highly dependent on the ploidy level (Diallo et al. 2015, unpublished). Therefore, the general linear model (1) was applied:

$Y_{i j k l}=\mu+P_{i}+f(P)_{i j}+V(P)_{i k}+B_{l}+e_{i j k l}$

where $Y_{i j k l}$ is the value of the phenotypic trait (gum yield, carbon, and nitrogen content), $\mu$ is the grand mean, $P_{i}$ is the effect of population $i, f(P)_{i j}$ is the random effect of family $j$ within population $i, V(P)_{i k}$ is the effect of the ploidy level $k$ within population $i, B_{l}$ is the effect of block $l$, and $e_{i j k l}$ is the residual error. Mixed families were also included in the model 
with each tree assigned to the proper ploidy.

In the second step, the analysis of growth and yield was made separately for diploid and polyploid trees (classified based on SSR banding pattern), because the molecular analysis identified these groups as genetically distinct (as presented in results below). The following linear model (2) was applied to test the provenance and family effects and - in the case of diploid families - to estimate variance components.

$$
Y_{i j k}=\mu+P_{i}+f(P)_{i j}+B_{k}+e_{i j k}
$$

In this model, families with mixed-ploidy were divided into sub-families according to the ploidy level allowing the assessment of performance of diploid and polyploid individuals within sub-families.

Phenotypic correlation coefficients between growth parameters and yield components were estimated as Pearson's correlation coefficients using SAS.

For gum color classes, a Fisher's exact test (Sokal and Rohlf 1981) was conducted as implemented in SAS to test whether gum color was independent of provenances, families, or levels of ploidy.

\section{Estimation of genetic parameters}

We estimated variance components and genetic parameters for diploid families in the progeny trial as regards gum yield (2012 and 2013) and growth traits using ASReml software version 3 (Gilmour et al. 2009) based on the general linear model (2). As presented in the results below, it was reasonable to assume that the diploid families were half sibs based on the mating system analysis.

The estimate of narrow-sense heritability $\left(\hat{h}_{\mathrm{ns}}^{2}\right)$ for each trait was calculated as the proportion of genetic variance over the total phenotypic variance (Falconer and Mackay 1996):

$\hat{h}^{2}{ }_{\mathrm{ns}}=\sigma_{\mathrm{A}}^{2} /\left(\sigma_{\mathrm{A}}^{2}+\sigma_{\mathrm{e}}^{2}\right)$

where $\sigma_{\text {A }}^{2}$ is the estimated additive genetic variance and $\sigma^{2}$ is the estimated error variance. In the case of half-sib families, the additive genetic variance is estimated as $4 \times \sigma_{\text {family }}^{2}$ (variance among the families) (Falconer and MacKay 1996). The standard errors of the narrow-sense heritability were estimated using ASReml software. The assumption of true half-sib relationship among offspring within families is crucial because genetic parameters are estimated from co-variances between relatives and the results are therefore highly sensitive to correct assumption on relationship (Borralho 1994). We also calculated the additive genetic co-efficient as the square root of $\sigma^{2}{ }_{\mathrm{A}}$ divided by the average mean of each quantitative trait to obtain a relative measure of quantitative genetic variation as suggested by Houle (1992). The joint estimate of genetic parameters was made across all provenances assuming the same level of additive genetic variation in all provenances. This assumption was supported by the molecular analysis that revealed the same level of genetic diversity (expected heterozygosity) among diploid individuals in the tested population (data not shown).

The genetic correlation of gum yield with growth traits such as diameter, crown, and height is important for indirect selection and prediction of correlated response (genetic gain). However, it was not possible to obtain reasonably precise estimates of genetic correlations in ASReml due to a limited sample size, but phenotypic correlation coefficients $\left(r_{\mathrm{p}}\right)$ between traits were estimated at individual tree basis within the diploid and polyploid group.

\section{Results}

\section{Relationship among siblings}

The three mainly diploid provenances (Daiba, Diamenar, and Kidira) all had high multilocus outcrossing rates $\left(t_{\mathrm{m}}\right.$ between 0.91 and 0.99 ; Table 1) that were not significantly different from 1 . The single-locus outcrossing rate $\left(t_{\mathrm{s}}\right)$ followed the trend of the multilocus estimate with the lowest value in Daiba $\left(t_{\mathrm{s}}=0.86\right)$. The estimated rate of biparental inbreeding $\left(t_{\mathrm{m}}-t_{\mathrm{s}}\right)$ was close to significant only in one provenance, Daiba $(0.054 \pm 0.027)$, suggesting that there could be a low rate of mating among relatives in this provenance. The estimated correlation between pollen gametes within families was low for the diploid provenances $\left(r_{\mathrm{p}}<0.05\right.$; Table 1$)$. In Daiba, the $r_{\mathrm{p}}$ was estimated to $0.005(0.056)$ corresponding to a very high number of effective pollen donors $\left(N_{\text {ep }} \sim 200\right)$ while $N_{\text {ep }}$ in Diamenar and Kidira was estimated to be $\sim 63$ and $\sim 27$, respectively. These results suggest that the studied diploid trees were outcrossed and pollinated by multiple pollen donors. Therefore, diploid trees within families could be assumed to be predominantly half sibs.

In the diploid provenances, the AMOVA based on binary data (microsatellite phenotype data) showed that the highest fraction of variation was due to within-family differences $(87 \%)$ as expected in half-sib families with the remaining fraction (13\%) due to variation among families (Table 2). When microsatellite genotypic data were used, the latter fraction was $15 \%$.

In the polyploids of the Ngane provenance, the observed variation within family was much lower than in diploids, only $59 \%$ with the remaining $41 \%$ found among families. This suggests that individuals within polyploid families are much closer related than individuals within diploid families, not supporting that these families mainly consist of half sibs. 
Table 1 Mating system parameters in diploid provenances of Acacia senegal based on eight microsatellite loci

\begin{tabular}{lllllll}
\hline Provenance & $N$ family & $N$ progeny & \multicolumn{1}{l}{$t_{\mathrm{m}}$} & \multicolumn{1}{l}{$t_{\mathrm{s}}$} & $t_{\mathrm{m}}-t_{\mathrm{s}}$ & $r_{\mathrm{p}}$ \\
\hline Daiba & 15 & 117 & $0.91(0.047)$ & $0.856(0.043)$ & $0.054(0.027)$ & $0.005(0.056)$ \\
Diamenar & 15 & 174 & $0.986(0.051)$ & $0.968(0.021)$ & $0.018(0.040)$ & $0.016(0.012)$ \\
Kidira & 15 & 95 & $0.981(0.057)$ & $0.932(0.037)$ & $0.048(0.050)$ & $0.039(0.078)$ \\
\hline
\end{tabular}

Numbers in parentheses indicate standard errors (S.E.)

\section{Population differentiation in relation to ploidy levels}

The PCoA of all 617 individuals in the progeny trial separated polyploid trees from diploid trees along axis 1 that explains $25 \%$ of the variation (Fig. 1). The only exception is the polyploid individuals from the Daiba provenance that clustered together with the group of diploid individuals from the four provenances.

The differentiation among family within each provenance ranged from 0.1 to 0.2 in diploids while differentiation among polyploid families was two times higher $\left(\varnothing_{\mathrm{AF}}=0.41\right.$, $P<0.001$; Table 2).

\section{Growth, gum yield, and gum properties}

A strong effect of ploidy was already observed for growth traits in provenances with both ploidy levels by Diallo et al. (2015, unpublished). However, gum yield was not significantly different between ploidy levels based on the comparison of families of different ploidy level within provenances $(P<0.34)$ as well as mixed-ploidy families (results not shown).

In the analysis restricted to diploid families, provenances and families were significantly different for height and diameter growth but not for crown diameter (Table 3). When the analysis was restricted to polyploid families, diameter and crown diameter were significantly different between families, while provenance effects were significant only for height and crown diameter. A strong effect of block on growth traits was noted for both diploid and polyploid families (Table 3) indicating the importance of micro-variation in growth conditions.

The analysis of carbon content in gum from the diploid and polyploid families did not show any significant variation among provenances and families, but polyploid families differed significantly in their nitrogen content (Table 3).

Based on the Munsell Soil Color chart, four different colors were observed: strong brown, reddish yellow, brownish, and very pale brown. Variation in gum coloration was not attributed to provenances and family in diploids. In contrast, gum
Table 2 Analysis of molecular variance showing the distribution of the variation within and among families of diploid and polyploid Acacia senegal based on the phenotype (binary microsatellite data) and genotype (co-dominant microsatellite data) with 9999 permutations

\begin{tabular}{llrrrrrr}
\hline & Source of variation & $d f$ & \multicolumn{1}{l}{ SS } & MS & Est. var. & Percent $^{\mathrm{a}}$ & $\varnothing_{\mathrm{AF}}$ \\
\hline Phenotype & & & & & & & \\
Diploid & & & & & & & \\
Diamenar & Among family & 14 & 150.818 & 10.773 & 0.510 & 11 & $0.105^{* *}$ \\
& Within family & 175 & 759.840 & 4.342 & 4.342 & 89 & \\
Daiba & Among family & 14 & 123.959 & 8.854 & 0.651 & 15 & $0.151^{*}$ \\
& Within family & 106 & 388.603 & 3.666 & 3.666 & 85 & \\
Kidira & Among family & 13 & 103.754 & 7.981 & 0.533 & 11 & $0.115^{* *}$ \\
& Within family & 89 & 365.877 & 4.111 & 4.111 & 89 & \\
Polyploid & & & & & & & \\
Ngane & Among family & 12 & 191.221 & 15.935 & 1.380 & 41 & $0.410^{*}$ \\
& Within family & 119 & 236.794 & 1.990 & 1.990 & 59 & \\
Genotype & & & & & & & \\
Diamenar & Among family & 14 & 162.769 & 11.626 & 0.620 & 14 & $0.140^{* *}$ \\
& Within family & 175 & 666.042 & 3.806 & 3.806 & 86 & \\
Daiba & Among family & 14 & 131.612 & 9.401 & 0.746 & 18 & $0.177^{* *}$ \\
& Within family & 106 & 367.322 & 3.465 & 3.465 & 82 & \\
Kidira & Among family & 13 & 96.688 & 7.438 & 0.560 & 14 & $0.143^{* *}$ \\
& Within family & 89 & 299.836 & 3.369 & 3.369 & 86 & \\
\hline
\end{tabular}

$d f$ degree of freedom, $S S$ sum of square, $M S$ mean square, Est. var. estimate of variance, $\phi_{A F}$ differentiation among family within provenance

$* P<0.001 ; * * P<0.000$

${ }^{\text {a }}$ Percentage of total variation 
Fig. 1 Principal cordinate analysis $(P C O A)$ of 617 diploid and polyploid progenies of Acacia senegal from the four provenances Daiba, Diamenar, Kidira and Ngane based on microsatelitte data. $D$ diploid, $P$ Polyploid

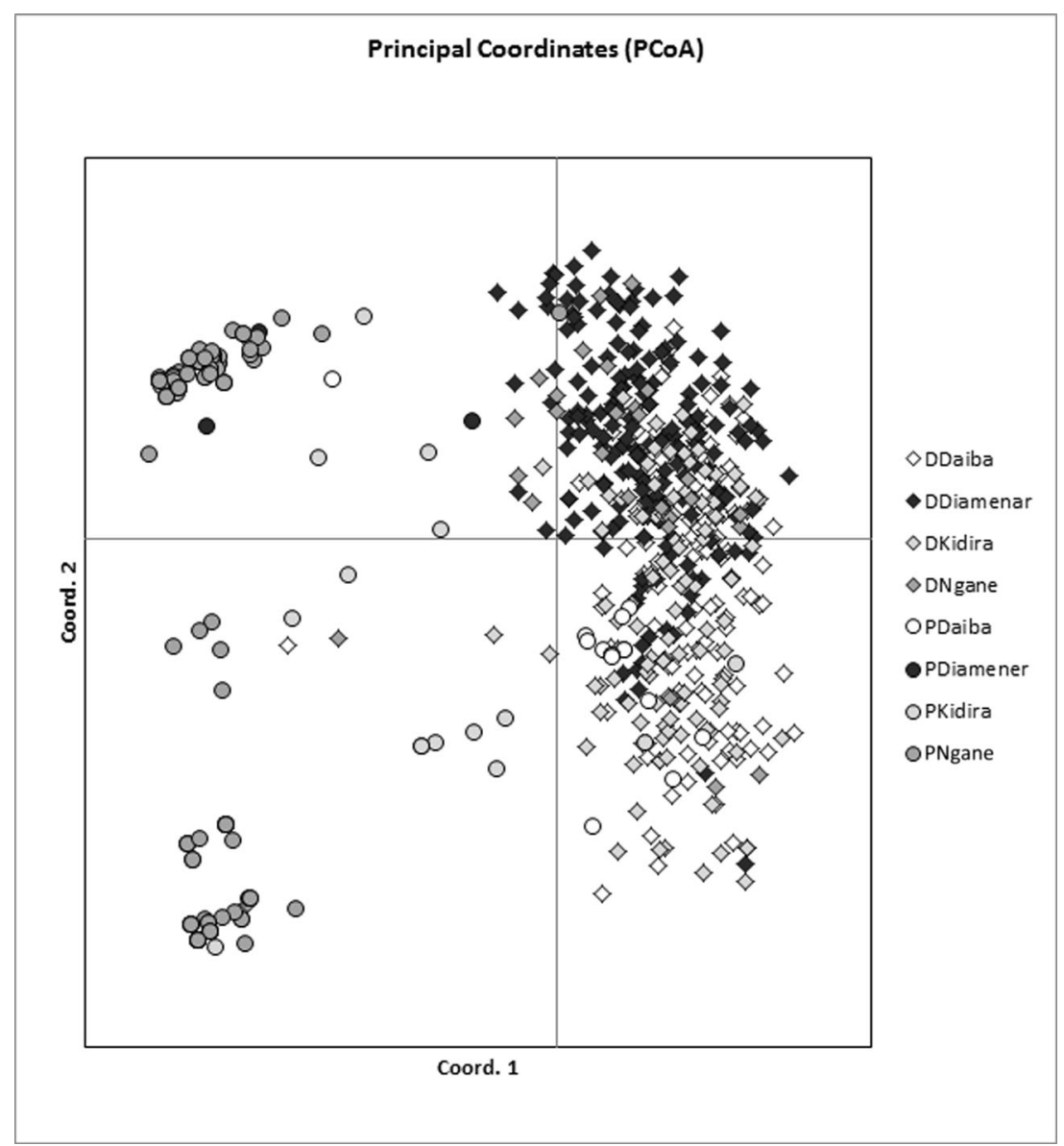

color variation was significantly different among polyploid provenances and families (Table 3).

Gum yields in 2012 and 2013 were highly dependent on provenances in the diploid families, while in the polyploid families a significant effect of provenance was only observed in 2012 (Table 3). Diploid families differed substantially and significantly in gum production only in 2013 whereas polyploid families were significantly different in both 2012 and 2013. However, the average gum production showed a highly significant effect of provenance and family for both diploids and polyploids (Table 3).

Even though ploidy level had no effect on gum yield, it is important to note that effect of provenances was to a large degree confounded with the ploidy level (Diallo et al. 2015, unpublished).

\section{Genetic parameters}

The genetic parameters were estimated with low precision as indicated by the standard error of narrow-sense heritability (Table 4), probably due to the small sample size of 47 diploid families with a total of 423 trees. Heritability estimates of growth and gum yield were relatively high, but heritability estimates for growth traits were in general lower than those for gum yield (Table 4).

The genetic variation of gum yield in 2013 and of yield average across the two years were relatively high as reflected by $\mathrm{CV}_{\mathrm{A}}$ values of 48 and $32 \%$, respectively.

\section{Variation in gum production}

The distribution of average gum yield in the progeny trial revealed large provenance-to-provenance variation (Fig. 2) and between family variation for both diploids and polyploids (Fig. 3). In diploids, the maximum mean was achieved in the Diamenar provenance with $301 \mathrm{~g}$ tree $^{-1}$ while the lowest gum yield average was recorded in the Daiba provenance with $165 \mathrm{~g}$ tree $^{-1}$ (Fig. 2). Regarding polyploids, average gum yield was significantly different between provenances with the highest yield obtained from the Ngane provenance with $227 \mathrm{~g}^{\text {tree }}{ }^{-1}$ whereas the lowest performance was observed in the Kidira provenance ( $87 \mathrm{~g}^{\text {tree }}{ }^{-1}$ ) (Fig. 2).

In general, there are no clear signs of a consistent effect of ploidy level on gum production (Fig. 2). In the Ngane and Daiba provenances, polyploid individuals tend to produce more gum than their diploid relatives (45 and $27 \%$, respectively) while the diploid individual trees performed better than 
Table $3 F$ tests for testing the significance of difference of growth and gum quality and yield over 2 years among and within provenances of each level of ploidy in Acacia senegal

\begin{tabular}{|c|c|c|c|c|c|c|}
\hline \multirow[t]{2}{*}{ Traits } & \multicolumn{2}{|c|}{ Provenance } & \multicolumn{2}{|c|}{ Family within provenance } & \multicolumn{2}{|c|}{ Block } \\
\hline & $F$ & $P>F$ & $F$ & $P>F$ & $F$ & $P>F$ \\
\hline \multicolumn{7}{|l|}{ Diploid } \\
\hline Height (m) & 3.99 & 0.008 & 1.54 & 0.01 & 6.43 & $<0.0001$ \\
\hline Diameter (cm) & 3.74 & 0.01 & 1.53 & 0.02 & 2.01 & 0.002 \\
\hline Crown average (m) & 1.58 & 0.19 & 1.08 & 0.34 & 2.50 & $<0.0001$ \\
\hline Gum nitrogen content $(\%)$ & 1.37 & 0.29 & 0.72 & 0.72 & 0.64 & 0.81 \\
\hline Gum carbon content $(\%)$ & 0.54 & 0.66 & 0.42 & 0.93 & 0.44 & 0.94 \\
\hline Gum color & - & 0.82 & - & 0.18 & - & 0.40 \\
\hline Gum yield in $2012\left(\mathrm{~g}\right.$ tree $\left.^{-1}\right)$ & 4.58 & 0.004 & 1.29 & 0.13 & 1.19 & 0.24 \\
\hline Gum yield in $2013\left(\mathrm{~g}\right.$ tree $\left.^{-1}\right)$ & 8.65 & 0.0003 & 2.36 & $<0.0001$ & 1.12 & 0.31 \\
\hline Average gum yield $\left(\mathrm{g}\right.$ tree $^{-1}$ ) & 7.69 & 0.0006 & 1.85 & 0.003 & 1.29 & 0.16 \\
\hline \multicolumn{7}{|l|}{ Polyploid } \\
\hline Height (m) & 3.51 & 0.017 & 1.35 & 0.17 & 4.65 & $<0.0001$ \\
\hline Diameter (cm) & 2.31 & 0.08 & 2.43 & 0.001 & 2.21 & 0.002 \\
\hline Crown average (m) & 2.7 & 0.05 & 1.78 & 0.02 & 2.29 & 0.001 \\
\hline Gum nitrogen content $(\%)$ & 8.75 & 0.04 & 12.31 & 0.02 & 5.13 & 0.06 \\
\hline Gum carbon content $(\%)$ & 3.06 & 0.16 & 1.14 & 0.45 & 3.42 & 0.12 \\
\hline Gum color & - & 0.007 & - & 0.04 & - & 0.57 \\
\hline Gum yield in $2012\left(\mathrm{~g}\right.$ tree $\left.^{-1}\right)$ & 3.38 & 0.04 & 1.90 & 0.03 & 2.51 & 0.0009 \\
\hline Gum yield in $2013\left(\mathrm{~g}\right.$ tree $\left.{ }^{-1}\right)$ & 1.47 & 0.24 & 1.87 & 0.03 & 1.69 & 0.04 \\
\hline Average gum yield ( $g$ tree ${ }^{-1}$ ) & 3.32 & 0.04 & 2.27 & 0.006 & 2.74 & 0.0003 \\
\hline
\end{tabular}

the polyploid individual trees in the Kidira provenance (Fig. 2).

Among families, the highest performances were recorded in families K14 (diploid) and NG21 (polyploid) with average yields of 867 and $423 \mathrm{~g}$ tree $^{-1}$, respectively.

\section{Phenotypic correlations between growth traits and gum yield in diploids and polyploids}

Phenotypic correlations between growth traits and gum yield were in general moderate for both ploidy levels (Table 5). The results revealed highly significant positive correlation coefficients between growth traits (height, diameter and crown diameter) and moderate correlation coefficients of growth traits with average gum yield in diploids (Table 5), while only crown average was significantly correlated with average gum yield in polyploids. The correlation between gum yield in 2012 and 2013 was strong for both diploids and polyploids $\left(r_{\mathrm{p}}=0.76\right.$ and $\left.r_{\mathrm{p}}=0.62\right)$.

\section{Discussion}

\section{Mating system in diploids and sibling relationship in polyploid $A$. senegal}

The present study is the first to present estimates of sibling relationship in A. senegal based on molecular markers. We find that diploid trees have outcrossing rates that are not significantly different from $1\left(t_{\mathrm{m}}=0.98 \pm 0.05\right)$ and with low correlation between pollen donors within families supporting that progeny within families are half sibs. These results are in line with a previous investigation on the reproductive biology of the species based on controlled crosses in Senegal (Diallo 1994). By comparing fruit production between crosspollinated and self-pollinated flowers, the author reported that cross-pollinated flowers gave higher fruit production, thus speaking in favor of a system promoting outcrossing. Another study on pollination biology of the species in India showed that no fruits developed from manually selfed flowers (Tandon and Shivanna 2001) confirming that diploid A. senegal, as many other predominantly bee pollinated Acacia species, is self-incompatible (Kenrick and Knox 1985).

We could not estimate the outcrossing rate of polyploid families as the allelic patterns of each locus did not fit with classic Mendelian segregation. However, the AMOVA showed that for open-pollinated polyploid families, a lower part of the molecular variation was distributed within families compared with the diploid families. This suggests that individuals within open-pollinated polyploid families are closer related than half sibs and therefore involve full-sib relationships (perhaps even self-pollinations) and/or even clones formed by apomixis. This result is in agreement with findings of Griffin et al. (2012) who reported a change in breeding 
Table 4 Genetic parameter estimates of growth and gum traits for the half sib families in diploid individuals of Acacia senegal

\begin{tabular}{|c|c|c|c|c|c|c|}
\hline Traits & $V_{\mathrm{A}}$ & $\hat{h}_{\mathrm{ns}}^{2}$ & $\mathrm{SE}\left(\hat{h}_{\mathrm{ns}}^{2}\right)$ & Lsmeans diploid & Lsmeans polyploid & $\mathrm{CV}_{\mathrm{A}}(\%)$ \\
\hline Height (m) & 0.05 & 0.21 & 0.15 & $4.53(0.06)$ & $4.89(0.14)$ & 5.0 \\
\hline Diameter $(\mathrm{cm})$ & 0.61 & 0.22 & 0.14 & $11.71(0.22)$ & $14.37(0.51)$ & 6.8 \\
\hline Crown (m) & $8.32 \mathrm{E}-07$ & 0 & 0 & $5.43(0.08)$ & $5.77(0.18)$ & 0.02 \\
\hline Gum nitrogen content (\%) & $2.86 \mathrm{E}-10$ & 0 & 0 & $0.39(0.01)$ & $0.34(0.02)$ & 0.004 \\
\hline Gum carbon content $(\%)$ & $5.80 \mathrm{E}-08$ & 0 & 0 & $39(0.73)$ & $38(1.11)$ & 0.06 \\
\hline Yield in $2012\left(\mathrm{~g}\right.$ tree $\left.{ }^{-1}\right)$ & 948 & 0.06 & 0.17 & $264(22)$ & $321(49)$ & 12 \\
\hline Yield in $2013\left(\mathrm{~g} \mathrm{tree}^{-1}\right)$ & 8216 & 0.73 & 0.27 & $189(17)$ & $216(38)$ & 48 \\
\hline Yield average ( $\mathrm{g}$ tree $\left.{ }^{-1}\right)$ & 4377 & 0.38 & 0.22 & $227(18)$ & $269(40)$ & 32 \\
\hline
\end{tabular}

Average performance (least square means) for both diploid and polyploid trees are provided for reference. Least square means (Lsmeans) of nontransformed data and standard errors (SE) are given for the two ploidy levels

$V_{A}$ the additive genetic variance, $\hat{h}_{n s}^{2}$ the narrow-sense heritability, $S E\left(\hat{h}^{2}{ }_{n s}\right)$ the standard errors of the heritability estimate, $C V_{A}$ the coefficient of additive genetic variance

system between diploid and neo-autotetraploid $A$. mangium trees where diploids were outcrossing while the neoautotetraploids were predominantly selfings.

The pattern observed in the PCoA coupled with the occurrence of very few triploids as reported by Diallo et al. (2015, unpublished), suggests that gene flow is relatively limited between diploids and polyploids, as individuals in general cluster relative to ploidy level rather than to geographic origin. Only exception is trees from the Daiba provenance where polyploids grouped together with diploid A. senegal. A few other polyploid individuals were also found among the diploid provenances. We speculate that only limited gene flow may occur between polyploids and diploids. Polyploids from the Ngane provenance appeared to be genetically isolated from diploids, which may suggest the presence of reproductive barriers between ploidy levels at least at some sites. The presence of reproductive barriers is supported by the clear differences in the partitioning of molecular variance within and among families between the two levels of ploidy, which may reflect

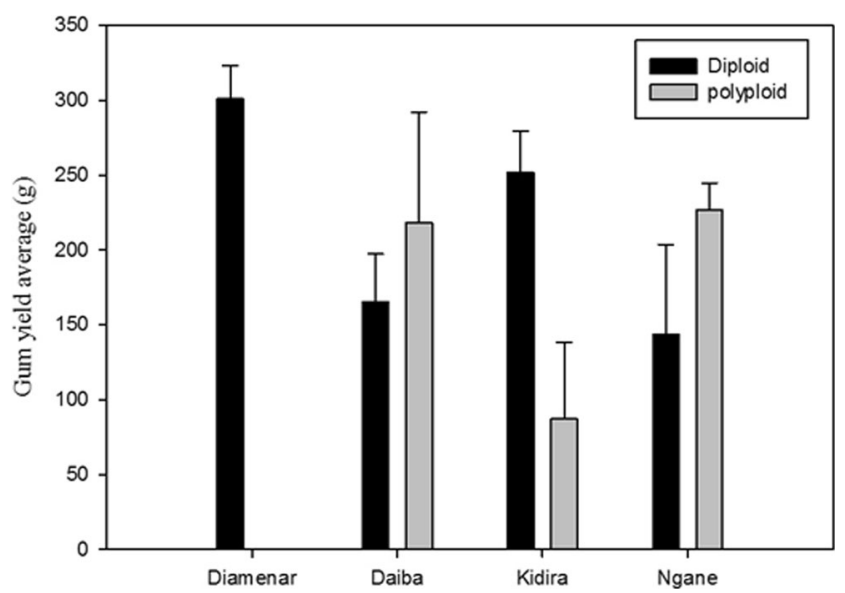

Fig. 2 Least square mean estimates of gum yield per tree for different ploidy levels within provenances of Acacia senegal. Standard errors shown with bars mating differences as described above. Reproduction with only few male donors and perhaps even self-pollinations and apomixes as suggested for polyploid Ngane is in line with the general observation of selfing and apomixis often being associated with polyploidy (Hörandl 2010). Polyploids are reported to exhibit higher rates of self-fertilization than related diploid species and $99 \%$ of the known apomictic plants are reported to be polyploids (Thompson and Ritland 2006). As newly formed polyploids in the beginning will represent minority cytotypes in the nature, uniparental mating provided by self-fertilization and apomixis is likely to increase the ability of newly formed polyploids to establish in an environment mainly represented by diploid plants (Husband 2000) and persist because backcrossing with the parental diploid species often results in sterile progeny (Stebbins 1971; Grant 1981). In addition, Stone (2002) reported that the transition from diploidy to polyploidy may be accompanied by a mating shift towards more selfing, through breakdowns in the selfincompatibility system. This has been reported in allotetraploid Tragopogon (Asteraceae) (Cook and Soltis 2000) where higher selfing rate was observed in tetraploids compared with diploids. Controlled crosses between diploid and polyploid trees would help to settle how well polyploid and diploid individuals of $A$. senegal are reproductively isolated from each other.

\section{Genetic improvement of $A$. senegal}

In genetic improvement, it is essential to estimate heritability and phenotypic variability for different traits to make successful decisions in breeding strategies. Earlier efforts regarding genetic improvement of African species have resulted in establishment of provenance trials and studies of germplasm using molecular markers, but studies on heritability estimates for gum production and fruit traits for major Sahelian tree species are basically absent (Ræbild et al. 2011). The present 
Fig. 3 Average performance in gum production per tree in 2012 and 2013 in diploid and polyploid families of Acacia senegal

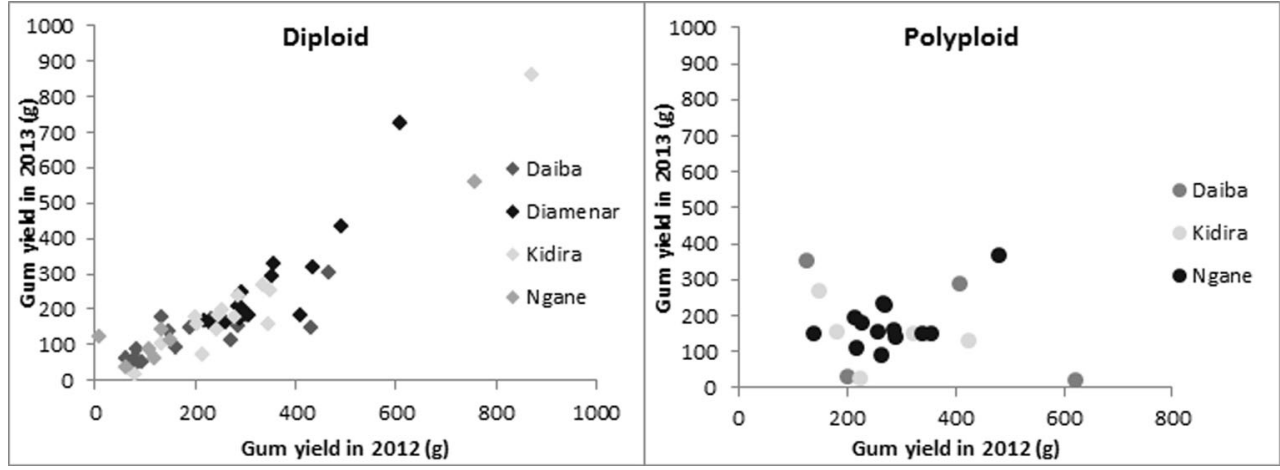

study is the first study that presents heritability estimates in A. senegal based on field testing where the relationship assumptions are tested by use of molecular data, and we found large genetic variations within and among provenances suggesting the possibility of improving gum production. The narrow-sense heritability of 0.38 for average gum yield in diploids thus suggests that gum yield is under moderate genetic control, and the high coefficient of additive genetic variation (CVA) suggests that a reasonably high genetic gain can be obtained from selection.

The finding of a genetic control of gum production is consistent with results by De Gonçalves et al. (2005) who reported a strong genetic control of rubber yield in Hevea brasiliensis.

In our study, it is interesting that the majority of the best families belong to the Diamenar provenance, which is close to the location of the test site (progeny trial). Survival rate of the Diamenar provenance was also higher compared with other provenances (Diallo et al. 2015, unpublished). Still, since the study does not include reciprocal testing, we can only speculate if this is an indication of genotype by environment interaction.

The average family mean for gum yield in our study ranged from 51 to $869 \mathrm{~g}^{-1} \mathrm{tre}^{-1}$ for diploids and from 103 to $423 \mathrm{~g}$ tree $^{-1}$ for polyploids, i.e., a large variability. Even though the accuracy of the heritability estimates for yield average was low $\left(\hat{h}_{\mathrm{ns}}^{2}=0.38 \pm 0.22\right)$ due to the limited sample size, it was possible to identify families and individual trees with high gum yield based on the average performance of both assessment years. Within these families are individuals that produced substantially above the average of $250 \mathrm{~g} \mathrm{ree}^{-1} /$ year as reported by Wekesa et al. (2009) and can be used as effective parents for the next-generation breeding.

We found that nitrogen content in the gum arabic differed between provenances and families in polyploids whereas carbon content seemed less affected by provenances, families, or ploidy level. On average, nitrogen content obtained in this study was $0.34 \%$ in polyploids and $0.39 \%$ in diploids. Previous studies have reported that the quality of the gum arabic could be affected by either the provenance, edaphic conditions, and climatic factors (Chikamai and Odera 2002) and vary between the varieties (senegal, kerensis, rostrata, and leiorhachis) (Lelon et al. 2010).

The low and moderate phenotypic correlation between gum yield and growth traits observed in our study implies that gum yield is only weakly dependent on the size of the tree. These results are in line with results of a previous study on the different varieties of the species in Kenya where no effect of tree size on gum yield was observed among varieties (senegal, kerensis, and leiorrhachis) (Wekesa et al. 2009). Gum production has for a long time been considered as physiological response to dryness and appeared to be negatively correlated with water storage in the soil as gum arabic is only produced

Table 5 Phenotypic correlation estimates between growth traits and gum yield in diploid (lower triangle) and polyploid (upper triangle) of Acacia senegal obtained using Person's correlation estimates

\begin{tabular}{|c|c|c|c|c|c|c|}
\hline Trait & Height in 2012 & Gum yield in 2012 & Gum yield in 2013 & Average gum yield & Crown diameter & Diameter \\
\hline Height in 2012 & & 0.02 & -0.03 & 0.00 & $0.44 * * *$ & $0.40 * * *$ \\
\hline Gum yield in 2012 & $0.25 * * *$ & & $0.62 * * *$ & $0.93 * * *$ & $0.30 * *$ & 0.17 \\
\hline Gum yield in 2013 & $0.21 * *$ & $0.76^{* * *}$ & & $0.86^{* * *}$ & 0.18 & 0.05 \\
\hline Average gum yield & $0.25 * * *$ & $0.95 * * *$ & $0.93 * * *$ & & $0.28 *$ & 0.13 \\
\hline Crown diameter & $0.59 * * *$ & $0.31 * * *$ & $0.28 * * *$ & $0.32 * * *$ & & $0.72 * * *$ \\
\hline Diameter & $0.61 * * *$ & $0.28 * * *$ & $0.27 * * *$ & $0.29 * * *$ & $0.69 * * *$ & \\
\hline
\end{tabular}

$* P<0.05 ; * * P<0.01 ; * * * P<0.001$ 
during the dry seasons when the trees are shedding leaves in contrast with the rainy season (Vassal and Dione 1993; Anderson 1995; Wekesa et al. 2009). Authors also reported that the species when grown in areas with more precipitation does not produce gum even in the dry season. Recently, Gray et al. (2013) reported that provenances of $A$. senegal that yielded more gum had low water use efficiency (WUE). This suggests that low WUE is actually associated to increased gum production. However, it will have to be tested whether trees with low WUE are prone to higher mortality under extreme and dry conditions.

The relatively high yield correlations across years ( $76 \%$ for diploids and $62 \%$ for polyploids) indicate that a breeding program may be based on only one year of yield assessment. However, we still recommend that the gum production should be assessed for more than 2 years to estimate the breeding potential because the correlations are substantially below 1 , and because the correlation in the present study was only estimated between two consecutive years. Preliminary results from Burkina Faso have indicated a low correlation between years (Lompo et al., personal communication), and the observed huge year-to-year variation in heritability between 2012 and 2013 also points towards the need of assessing average gum yield across some years.

The present study did not allow us to study genotype by environment interactions. Field trials at environmentally different sites are needed in order to guide whether breeding programs should be divided into multiple zones, and if so guided by which environmental parameters. An interesting option will be establishment of multiple Breeding Seed Orchard (BSO) as part of continued breeding programs as, e.g., discussed by Dhakal et al. (2005) or clonal seed orchard for both high yielding diploid and polyploid individuals. In the case that polyploids are apomictic, the clonal propagation of superior genotypes could be made through seed.

\section{Conclusion}

This study stresses the importance of using DNA markers in assessing the mating system and the relationship within and among families as part of the estimation of quantitative genetic parameters to support breeding activities in A. senegal. We found that diploid and polyploid families differed significantly in their likely sibling relationship within open-pollinated families. We observed large genetic variation for growth traits and gum yield between provenances and among diploid and polyploid families. For gum quality, differences were only observed within polyploid provenances and families. The genetic coefficient of variation for gum yield was found to be high, which indicates that selection of the next generation's trees for gum yield is possible. We recommend that the gum production should be measured over multiple years to verify and quantify the observed huge year-to-year variation in heritability and genetic coefficient of variation and also to test genotype by climate interactions. Also, more field trials will be required to increase knowledge about genotype by environment interactions. Unfortunately, no estimates of genetic correlations were obtained from this study because of the fairly low sample size.

Our results report large variation at provenance, family, and individual levels in gum production. The presence of genetic control in gum production implies that improvement of gum production and gum export in Senegal and in Africa could be based on both family and individual selection. This material could be further used for future forest restoration programs. Further studies with sufficient number of families and individuals will strengthen the accuracy of our heritability estimates and allow estimates of genetic correlation between traits.

In polyploids, more attention should be given to the fact that the offspring families seem not to be half sibs. In cases of clones, estimates of genetic parameters will be straightforward as broad sense heritability will be the relevant parameter and easily estimated from the variation between genotypes (clones). In the case of full sibs, the estimation is more complicated since dominance variance and the type of inheritance involved (i.e., disomic or tetrasomic inheritance) will influence the estimates, and offspring from open pollinations can therefore not provide sufficient information. Further studies are therefore needed for determination of the mating system involved in polyploids.

Acknowledgments The authors would like to express our sincere thanks to Momar Wade and Ibra Padane for technical assistance during the field work, Lene Hasmark Andersen for genotyping support, and Preben Frederiksen for assisting with the $\mathrm{CN}$ analyzer. This research is funded by the Islamic Development Bank (IDB) under the PhD Merit Scholarship program and by the University of Copenhagen, Denmark.

Conflict of interest The authors declare that they have no conflict of interest

Data Archiving Statement Data will be archived in DRYAD

\section{Appendix}

Table 6 Differences in frequency of polyploids and diploids of Acacia senegal in the progeny trial

\begin{tabular}{lrlll}
\hline Provenances & Ngane & Daiba & Diamenar & Kidira \\
\hline No. diploid families & 2 & 10 & 12 & 10 \\
No. of polyploid families & 6 & - & - & - \\
No. of mixed families & 7 & 5 & 3 & 5 \\
No. of diploid individuals & 28 & 132 & 178 & 101 \\
No. of polyploid individuals & 136 & 14 & 3 & 16 \\
$\begin{array}{l}\text { Percentage of polyploid } \\
\quad \text { individuals (\%) }\end{array}$ & 83 & 10 & 2 & 14 \\
\hline
\end{tabular}


Open Access This article is distributed under the terms of the Creative Commons Attribution 4.0 International License (http:// creativecommons.org/licenses/by/4.0/), which permits unrestricted use, distribution, and reproduction in any medium, provided you give appropriate credit to the original author(s) and the source, provide a link to the Creative Commons license, and indicate if changes were made.

\section{References}

Anderson DMW (1995) Gums - ancient and modern commercial products. NFT Highlights NFTA 95-01. Winrock International, Arkansas

Assoumane A, Vaillant A, Mayaki AZ, Verhaegen D (2009) Isolation and characterization of microsatellite markers for Acacia senegal (L.) Willd., a multipurpose arid and semi-arid tree. Mol Ecol Resour 9: $1380-1383$

Assoumane A, Zoubeirou AM, Rodier-Goud M, Favreau B, Bezancon G, Verhaegen D (2013) Highlighting the occurrence of tetraploidy in Acacia senegal (L.) Willd. and genetic variation patterns in its natural range revealed by DNA microsatellite markers. Tree Genet Genomes 9:93-106

Ballal ME, El Siddig EA, Elfadl MA, Luukkanen O (2005) Gum arabic yield in differently managed A. senegal stands in western Sudan. Agrofor Syst 63:237-245

Borralho NMG (1994) Heterogeneous selfing rates and dominance effects in estimating heritabilities from open-pollinated progeny. Can J For Res 24:1079-1082

Butcher PA, Moran GF, Perkins HD (1998) RFLP diversity in the nuclear genome of Acacia mangium. Heredity 81:205-213

Chikamai BN, Odera JA (2002) Commercial plant gums and gum resins in Kenya. Sources of alternative livelihood and economic development in the drylands of Kenya. Executive Printers, Nairobi-Kenya

Cook LM, Soltis PS (2000) Mating systems of diploid and allotetraploid populations of Tragopogon (Asteraceae). II. Artificial populations. Heredity 84:410-415

Coulibaly K (1988) Le Gommier et les actions en cours pour sa rehabilitation au Mali. In: SYGGA III, Troisieme Symposium sur le gommier et la gomme arabique, Saint Louis, Senegal, pp. 25-31

Couteaudier YT (2007) Export marketing of Sudanese gum arabic. Sudan multi donor trust funds, technical secretariat. The World Bank, Khartoum, p 45

De Gonçalves PS, De Moraes MLT, Bortoletto N, Da Costa RB, Gonçalves ECP (2005) Genetic variation in growth traits and yield of rubber trees (Hevea brasiliensis) growing in the Brazilian state of São Paulo. Genet Mol Biol 4:765-772

Dhakal LP, Lillesø JPB, Kjær ED, Jha PK, Aryal HL (2005) Seed sources of agroforestry trees in a farmland context - a guide to tree seed source establishment in Nepal. Forest \& Landscape Development and Environment Series 1, Hørsholm, Denmark

Diallo I (1994) Etude de quelques aspects de la biology de la reproduction de Acacia senegal (L.) Willd. Memoire de Confirmation, Direction de Recherches sur les Productions Forestieres, p. 38

Diallo AM, Kjær ED, Ræbild A, Petersen KK, Nielsen LR (2015) Polyploidy confers superiority to trees grown under stressful conditions: A case study of Acacia senegal (L) Willd. in Sahel region of West Africa (Submitted to Botanical Journal of the Linnean Society)

Fagg CW, Allison GE (2004) Acacia senegal and the gum arabic trade. Oxford. Tropical forestry. Papers 42 Alden Group, Oxford, p 261

Falconer DS, Mackay TFC (1996) Introduction to quantitative genetics, 4th edn. Pearson Education Limited Edinburgh Gate, Essex, p 459

Gilmour AR, Gogel BJ, Cullis BR, Thompson R (2009) ASReml user guide release 3.0. VSN International Ltd, Hemel Hempstead, p 398
Grant V (1981) Plant speciation, 2nd edn. Columbia University Press, New York

Grattapaglia D, Kirst M (2008) Eucalyptus applied genomics: from gene sequences to breeding tools. New Phytol 179:911-929

Grattapaglia D, Plomion C, Krist M, Sederoff RR (2009) Genomics of growth traits in forest trees. Curr Opin Plant Biol 12:148-156

Gray A, Odee D, Cavers S, Wilson J, Telford A, Grant F, Diouf M, Ochieng J, Grant F, Stott A (2013) Does geographic origin dictate ecological strategies in Acacia senegal (L.) Willd.? Evidence from carbon and nitrogen stable isotopes. Plant Soil 369:479-496

Griffin A, Vuong T, Vaillancourt R, Harbard J, Harwood C, Nghiem C, Thinh $\mathrm{H}$ (2012) The breeding systems of diploid and neoautotetraploid clones of Acacia mangium Willd. in a synthetic sympatric population in Vietnam. Sex Plant Reprod 25:257-265

Henery ML, Moran GF, Wallis IR, Foley WJ (2007) Identification of quantitative trait loci influencing foliar concentrations of terpenes and formylated phloroglucinol compounds in Eucalyptus nitens. New Phytol 176:82-95

Hörandl E (2010) The evolution of self-fertility in apomictic plants. Sex Plant Reprod 23:73-86

Houle D (1992) Comparing evolvability and variability of quantitative traits. Genetics 130:195-204

Huff DR, Peakall R, Smouse PE (1993) RAPD variation within and among natural populations of outcrossing buffalograss Buchloe dactyloides (Nutt) Engelm. Theor Appl Genet 86:927-934

Husband BC (2000) Constraints on polyploid evolution: a test of the minority cytotypes exclusion principle. Proc R Soc B 267:217-227

Kenrick J, Knox RB (1985) Self-incompatibility in the nitrogen-fixing tree, Acacia retinodes: quantitative cytology of pollen tube growth. Theor Appl Genet 69:481-488

Korbo A, Kjær ED, Sanou H, Ræbild A, Jensen JS, Hansen JK (2013) Breeding for high production of leaves of baobab (Adansonia digitata $\mathrm{L}$ ) in an irrigated hedge system. Tree Genet Genomes 3: $779-793$

Larsen AS (2010) Gene flow and genetic structure in wild fruit trees: DNA-marker based studies of Adansonia digitata, Vitellaria paradoxa, Parkia biglobosa and Malus sylvestris. $\mathrm{PhD}$ thesis, University of Copenhagen, Denmark

Larwanou M, Raebild A, Issa R, Kjaer ED (2010) Performance of Acacia senegal (L.) Willd provenances in dryland Savannah of Niger. Silvae Genet 59:210-218

Lelon JK, Jumba IO, Keter JK, Wekesa C, Oduor FDO (2010) Assessment of physical properties of gum arabic from Acacia senegal varieties in Baringo District, Kenya. African J Plant Sci 4: 95-98

MNS, (2008) Gum arabic. Bulletin market news service. International Trade Center. Quarterly Edition. p 41

Odee DW, Wilson J, Cavers S (2012) Prospects for genetic improvement of Acacia senegal. Can molecular markers approaches deliver better gum yield and quality? Gum arabic. Royal Society of Chemistry, Cambridge, pp 99-109

Otto F (1990) DAPI staining of fixed cells for high-resolution flow cytometry of nuclear DNA. Methods Cell Biol 33:105-110

Ouédraogo M (2001) Analyse statistique dans le cadre de l'amélioration génétique forestière en zone soudano-sahélienne: Cas d'un essai de provenances d'Acacia senegal. Mémoire de fin d'études DEA. Unité de statistique et Informatique Appliquée-Faculté Universitaire des Sciences Agronomiques de Gembloux. $97 \mathrm{p}$

Peakall R, Smouse PE (2012) GenAlEx 6.5: genetic analysis in Excel. Population genetic software for teaching and research - an update. Bioinformatics 28:2537-2539

Raddad EAY, Luukkanen O (2006a) Adaptive genetic variation in wateruse efficiency and gum yield in Acacia senegal provenances grown on clay soil in the Blue Nile region, Sudan. For Ecol Manag 226: 219-229 
Raddad EY, Luukkanen O (2006b) The influence of different Acacia senegal agro-forestry systems on soil water and crop yields in clay soils of the Blue Nile region, Sudan. Agric Water Manag $87: 61-72$

Ræbild A, Larsen AS, Jensen JS, Ouedraogo M, De Groote S, Van Damme P, Bayala J, Diallo BO, Sanou H, Kalinganire A, Kjær ED (2011) Advances in domestication of indigenous fruit trees in the West African Sahel. New For 41:297-315

Ritland K (2002) Extensions of models for the estimation of mating systems using $\mathrm{n}$ independent loci. Heredity 88:221-228

SAS Institute (2014) SAS/STAT user guide. SAS Institute Inc., Gary

Sokal RR, Rohlf FJ (1981) Biometry: the principles and practice of statistics in biological research. Freeman and Company, New York

Soloviev P, Jacques D, Zerbo GC, Lompo D (2010) Production de semences améliorées d'Acacia senegal. Bois For Trop 303:67-82

Sprent JI, Odee DW, Dakora FD (2010) African legumes: a vital but under-utilized resource. J Exp Bot 61:1257-1265

Stebbins GL (1971) Chromosomal evolution in higher plants. Edward Arnold, London

Stone JL (2002) Molecular mechanisms underlying the breakdown of gametophytic self-incompatibility. Q Rev Biol 77:17-32
Tandon R, Shivanna KR (2001) Pollination biology and breeding system of Acacia senegal. Bot J Linn Soc 135:251-262

Thompson SL, Ritland K (2006) A novel mating system analysis for modes of self-oriented mating applied to diploid and polyploid arctic Easter daisies (Townsendia hookeri). Heredity 97:119-126

Touré S (2009) Gum arabic and gum resin. Report, Bulletin Market News Service (MNS). International Trade Centre, quarterly edition. p 39

Vassal J and Dione M (1993) Experimental study of the means of production of gum trees of Acacia senegal; looking back on the gum tree development programmes in the Senegalese Sahel. In: Natural Resources and Social Conflicts in the Sahel. Proceedings of the 5th Sahel Workshop 180-191

Wate I (1979) Regression de la gommeraie et desertification au Manga. Environnement Africain. Cahiers d'Etude du Milieu et d'Amenagement du Territoire 37:1-18

Wekesa C, Makenzi P, Chikamai BN, Lelon JK, Luvanda AM, Muga M (2009) Gum arabic yield in different varieties of Acacia senegal(L.) Willd in Kenya. African J Plant Sci 11:263-276

Wong CK, Bernando R (2008) Genome wide selection in oil palm: increasing selection gain per unit time and cost with small populations. Theor Appl Genet 116:815-824 